\title{
Erratum to: Fuzzy Logic Determination of Lithologies from Well Log Data: Application to the KTB Project Data set (Germany)
}

\author{
David Bosch • Juanjo Ledo $\cdot$ Pilar Queralt
}

Published online: 2 August 2013

(C) Springer Science+Business Media Dordrecht 2013

Erratum to: Surv Geophysics (2013) 34:413-439
DOI 10.1007/s10712-013-9242-2

Due to an unfortunate misunderstanding, the legend of Figs. 6 and 7 was omitted.

We sincerely apologize for the confusion that may arise from this error.

Below are included the mentioned figures with their corresponding legends.

The online version of the original article can be found under doi:10.1007/s10712-013-9242-2.

D. Bosch $(\bowtie) \cdot$ J. Ledo $\cdot$ P. Queralt

Departament de Geodinàmica i Geofísica, Facultat de Geologia, Universitat de Barcelona,

C/Martí i Franquès, s/n, 08028 Barcelona, Spain

e-mail: dbosch@ub.edu 

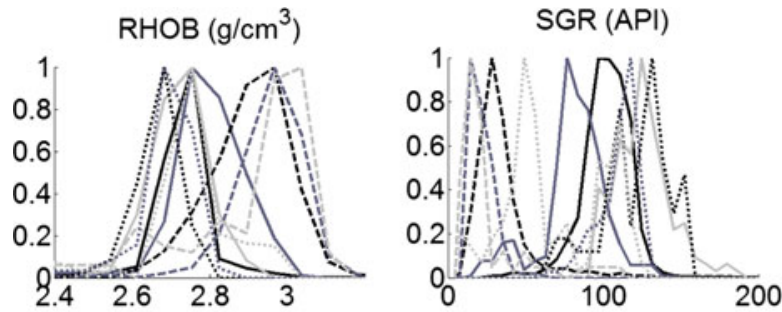

\begin{tabular}{|l|}
\hline - Biotite-paragneiss \\
- Hornblende gneiss \\
- Potassium-feldspar gneiss \\
---Amphibolite \\
---Metagabbro \\
--Ultramafitite \\
-...-Aplite \\
-... Lamprophyre \\
Other
\end{tabular}
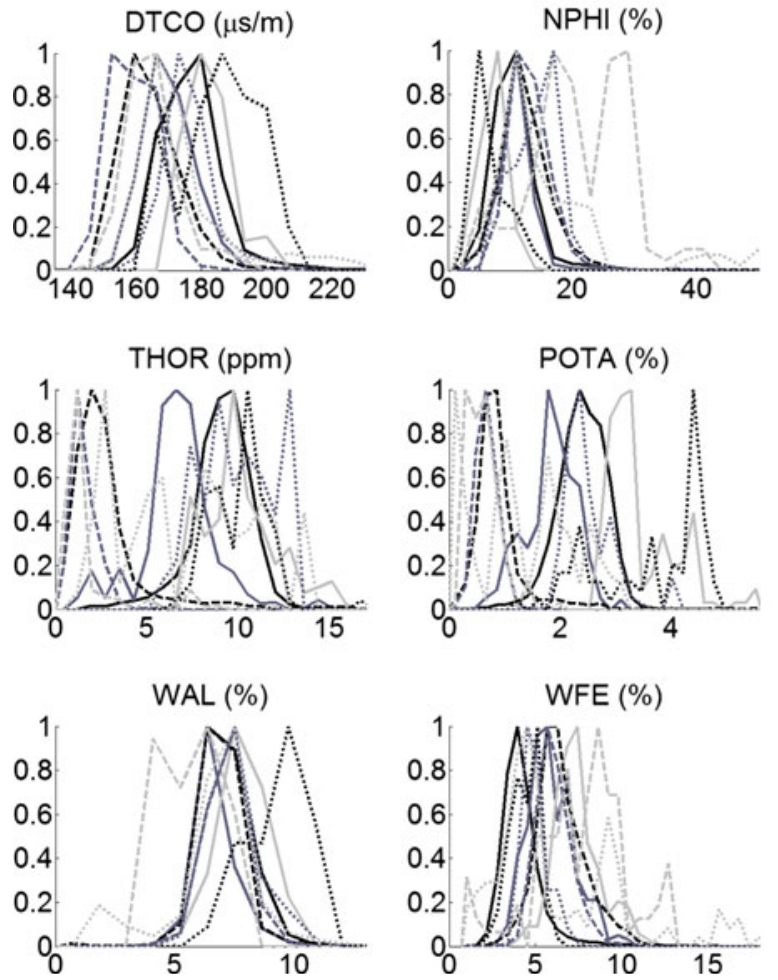

Fig. 6 Plots of the piecewise linear membership functions obtained from the training well data. There are 30 bins for each histogram 

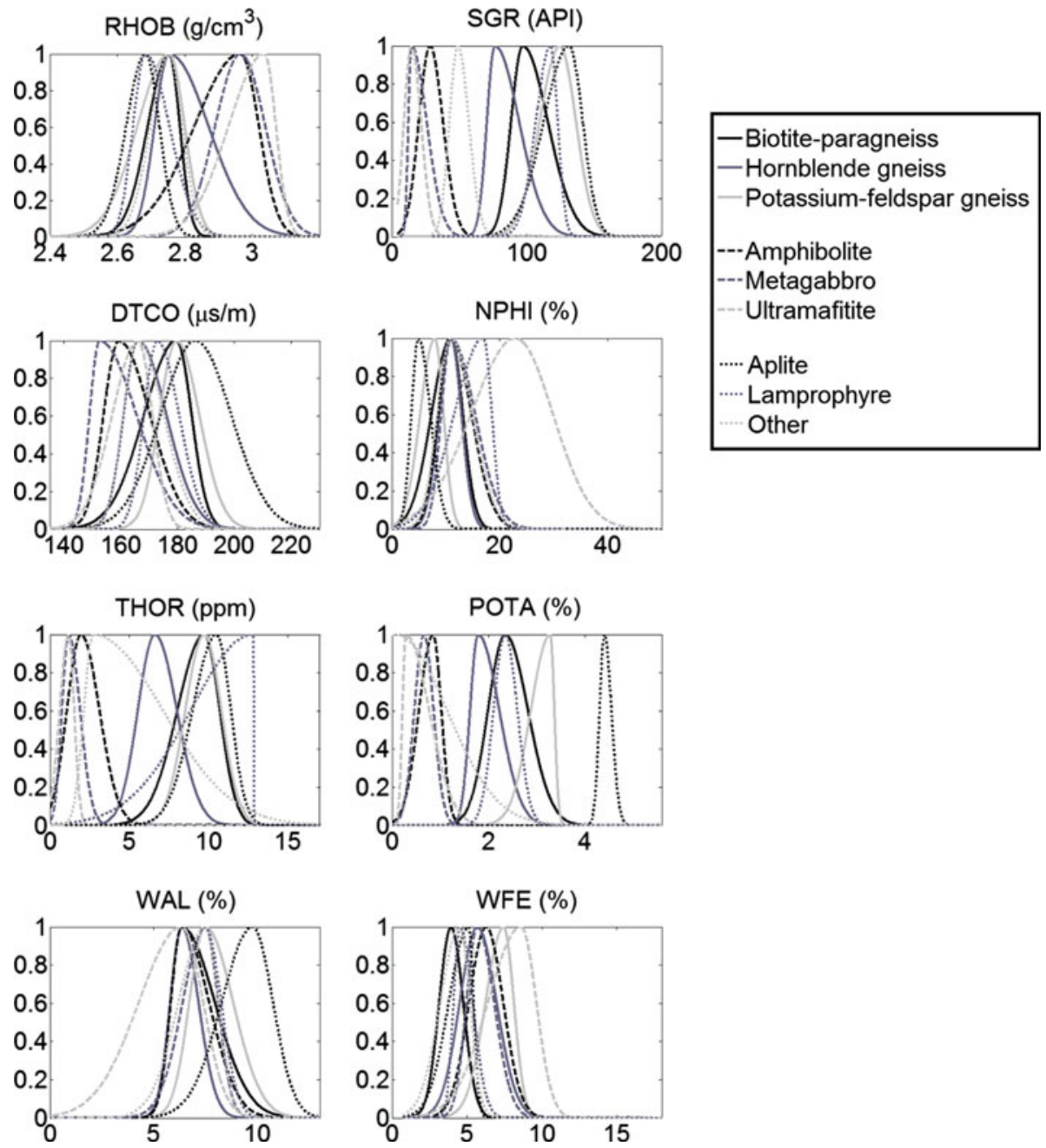

Fig. 7 Plots of the unnormalized double gaussian membership functions obtained from the training well data. There are 30 bins for each histogram 